\title{
Universal Product Code (Barcode) and Retailing Performance of Supermarkets in Nigeria
}

\author{
Ezechirinum Amadi ${ }^{1} \quad$ Osagie Leslie Uwabor Ph.D ${ }^{2 *}$ \\ School of Business Education, Department of Accounting, Federal College of Education (Technical), Omoku. \\ Rivers State - Nigeria \\ Corresponding Author: Osagie Leslie Uwabor' P.M.B 488 Uniport Post Office, Port Harcourt Nigeria
}

\begin{abstract}
This study examined the relationship between Universal Product Code and Retailing Performance of Supermarkets in Nigeria. The specific objectives of the study were to investigate the influence of bar code formatting and bar code encoding on retailing performance. The study adopted the cross sectional research study. The choice of this approach is because it will scientifically examine the situation on ground and empirically analyze it to get result that can be generalized on the accessible population. Based on the research questions, a research questionnaire was designed and one hundred (100) copies were distributed to the sample population which was determined by convenient sampling techniques. After data cleaning, a total of ninety two (92) copies of the distributed questionnaire were retrieved. These copies were analyzed and the hypotheses were tested using the Pearson's Product Moment Correlation Coefficient with the aid of SPSS Version 22.0. The result revealed that; there is a significant relationship between bar code formatting and sales volume, bar code formatting and profitability, bar code encoding and sales volume, bar code encoding and profitability. The study recommends that Supermarkets should endeavour to update regularly, their products barcode fields to ensure that their wide range of products are always captured and enlisted in the field to ease up the purchase and sales activities of the supermarkets; Regular training exercise should be organized to educate the staff of the supermarkets on how to manage the barcode fields and to efficiently handle issues relating to formatting and encoding of the barcode fields.
\end{abstract}

Keywords: Universal, Product, Code, Retailing, Performance, Barcode Formatting, Barcode Encoding, Sales Volume and Profitability.

DOI: $10.7176 / \mathrm{EJBM} / 12-29-03$

Publication date:October $31^{\text {st }} 2020$

\section{Introduction}

In recent times, the retailing business has been revolutionized in such a way that the outlets established to render such retailing services to the public must have to standardize their products and services in order to render quality services and retain the patronage and loyalty of their customers. Jenget al. (2008) observed that the strong competition in the retailing industry particularly within supermarkets, have necessitated the need for urgent action by management of those supermarkets to institute necessary measures that will direct their actions towards establishing fast customer response mechanisms that will enhance their service quality towards customers and also reduce that time spent by customers in searching for desired products within the shelves of these supermarkets. Obviously, the global business environment has metamorphosed into a small village of advanced cooperation in which the failure of any business unit to integrate her service/product into the scope of this global nomenclature may result in the severe loss of resources by such entities, therefore, a supermarket that desires to remain actively engaged within this global village and thus cooperatively active, must devise means that would help them provide quality services to their clients/customer in order to provide for themselves, an edge in service quality when compared with other contending competitors.

Nepelski (2006) observed, that the ability of retail outlets to retain loyal customers and consequently, enjoy enormous volume of sales and thus extreme profitability is dependent on the ability of the business to institute a positive business plan that will enable these businesses to reach out to customers with positive and quick service contexts that will yield immediate benefits to such customers.

The universal product code has been identified as one of the contemporary marketing tools that enables businesses grade, departmentalize and position their products in such a way that it will be easy for customers and staff of supermarket to identify and quantify products according to their codes (Mose et al., 2013). The universal product code therefore provide supermarkets with a platform which allows them to grade and position their wide range of products according to their types, description; size etc which makes it very easy for customers to identify and make choices, and also for staff to identify prices at the desk and provide prompt services to customers which will most often yield satisfaction and customer loyalty to such supermarkets (Angeles \& Nath, 2007).

Barcode data collection technology is an effective way to improve the bottom line and meet the competitive challenges organizations face every day (Darlington, 2009). When integrated into the data collection technology and other procurement and sales systems, barcodes provide a rapid, accurate and efficient means to collect, prices, transmit record and manage data in a variety of industries. Thus, retailers, package delivery, warehousing and 
distribution and point of service applications can all benefit from the use of automated identification, such as bar coding system (King, 2010).

From the empirical point of view, only but a few studies have been carried out on Universal Product Code related construct/concept (Nepelski, 2006; Jau-Jeng et al., 2008; Mosse et al., 2013; Akoth, 2014). In the Nigeria context, there is no empirical study on universal product code and retailing performance as it relates to supermarkets, a gap in literature thus exist and our departure point is to empirically investigate the relationship between universal product code and retailing performance of supermarkets in Port Harcourt.

\section{Statement of the Problem}

Over the year, the retail industry in Nigeria has evolved and grown significantly, gradually transcending from the traditional bricks-and mortar system to the modern click-and-mortar system. This involves buying and selling at open air market in both the urban and rural areas of the nation. The rate at which Nigerians patronize supermarkets and related retail shops has been increasing considerably overtime, and the volume of products which these supermarkets carry has made it relevant for the supermarkets to integrate into their operational context, the application of the Universal Product Code (Barcode) to enable them assort these lines of products into easily accessible compartments. However, it is pertinent to note that despite the numerous benefits associated with the use of the product barcode, many supermarkets have not completely integrated these into their context of functioning. Also, some of those that have started using this Universal Product Code have not been able to effectively establish its full operationalization which has impacted negatively on their performance.

It is sad to note that the available literature on Universal Product Code and retailing performance is scanty, also, the available empirical study in this area have not explored the dimensions adopted in this study, this as such leaves a gap in literature which this study intends to fill. It is against this background therefore, that this study investigates the effect of Universal Product Code on the retailing performance of supermarkets in Nigeria.

\section{Conceptual Framework}

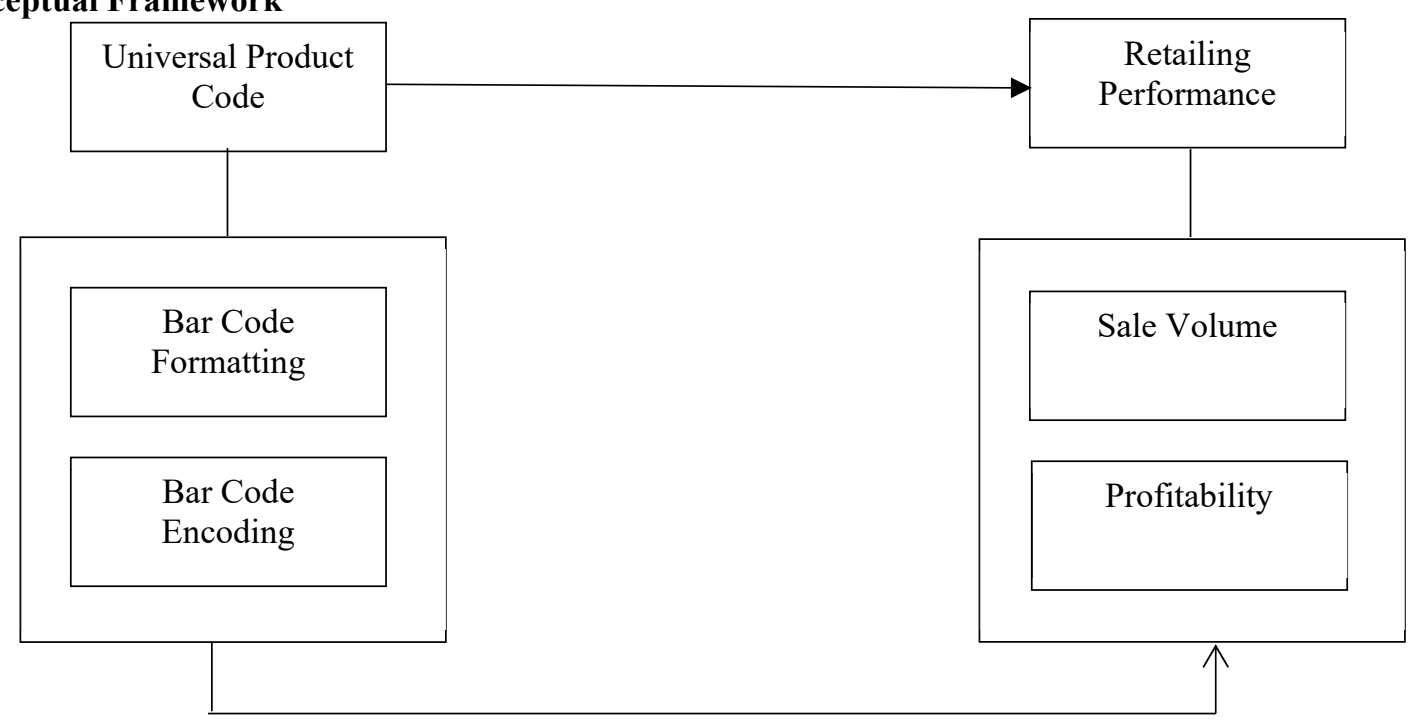

Figure 1: Conceptual framework on the relationship between Universal Product Code and retailing performance of supermarkets in Nigeria

Source: Researcher's conceptualization from review of related literature, 2020

\section{Objectives of the Study}

The general objective of this study is to examine the relationship between Universal Product Code and retailing performance of supermarkets in Port Harcourt. The specific objectives include:

i) To examine the relationship between barcode formulating and profitability of supermarkets in Nigeria.

ii) To examine the relationship between barcode formulating and sales volume of supermarkets in Nigeria.

iii) To ascertain the extent of relationship between barcode encoding and profitability of supermarkets in Nigeria

iv) To ascertain the extent of relationship between barcode encoding and sales volume of supermarkets in Nigeria 


\section{Research Questions}

i) To what extent does barcode formulating influence sales volume of supermarkets in Nigeria?

ii) To what extent does barcode encoding influence the profitability of supermarkets in Nigeria?

iii) To what extent does barcode formulating influence profitability of supermarkets in Nigeria?

iv) To what extent does barcode encoding influence sales volume of supermarkets in Nigeria?

\section{Research Hypotheses}

The following hypotheses guided the researcher in this study.

Ho1: There is no significant relationship between barcode formulating and sales volume of supermarkets in Nigeria. Ho2: There is no significant relationship between barcode formulating and profitability of supermarkets in Nigeria. Ho3: There is no significant relationship between barcode encoding and sales volume of supermarkets in Nigeria. Ho4: There is no significant relationship between barcode encoding and profitability of supermarkets in Nigeria.

\section{Review of Related Literature \\ Theoretical Foundation}

The most relevant theory to this study is Van Woole Theory (2005). This theory explains critical determinants of successful automated transactions. Woole (20005) presents two areas in which purchasing performance can be measured, purchasing effectiveness and purchasing efficiency. The theory states that purchasing effectiveness is a measure of what has been accomplished and purchasing efficiency is a measure of what resources has been used to accomplish it. Based on Van Wools (2005) four dimensions, cost/price, product/quality, logistics and organization are identified. Thus enhancing retailing performance of supermarkets through the use of Universal Product Code can be capitalized through this theory. This study therefore is anchored on the Van Woole theory.

\section{Concept of Universal Product Code}

Universal Product Codes (Barcodes) are "printed horizontal strips of vertical bars used for identifying specific items". A "scanning device reads the barcode by moving a beam across the symbol". The first barcode system was developed around the 1940s and 1950s, since then people have become very accustomed to their use, through common applications such as in retail and grocery markets (Burnell, 1998).

As with the history of Universal Product Codes (barcodes), most works provide, to some degree, background information regarding the development of barcode standards. While most sources examine a number of standards, there is a common facet among all works in that they discuss the importance of the UPC (Universal Product Code) standard. One work in particular by Brown (1997) provides a thorough insight into the development of the Universal Product Code standard, including its formation and in depth historical aspects. Most works on barcodes include some background information regarding the importance and development of the Universal Product Code and the Uniform Code Council (UCC).

Palmer (1995) offers a broad range of technical information on Universal Product Code (barcode) standards and symbologies. A symbology is "the term used to describe how information is encoded into the physical attributes of the bars and spaces", and, as such, it is of significant importance to barcodes. This symbology "will allow for the co-existence of symbologies already being used and can be supported by existing barcode equipment" (Heinen, Coyle \& Hamilton, 2003).Barcode technology has been used for decades and during this time has proved itself as a reliable performer. Testament to this is the versatility in which the technology can be adapted to suit specific applications.

\section{Barcode Formatting}

The decoding of a message is how an audience member is able to understand, and interpret the message. It is a process of interpretation and translation of coded information into a comprehensible form (Swartz, 1999). Barcode formatting entails understanding the readability of the assigned fields attached to the products by staff so that it is easy to read and detect the assortments and prices of the products by the staff of the supermarkets (Brown, 1997). Through the process of barcode formatting the decoding party is trying to reconstruct the idea by giving meanings to symbols and by interpreting the message as a whole. Effective communication is accomplished only when the message is received and understood in the intended way. However, it is still possible for the message recipient to understand a message in a completely different way from what the encoder was trying to convey. This is when "distortions" or "misunderstanding" arise from "lack of equivalence" between the two sides in communicative exchange (Cohen, 1994).

\section{Barcode Encoding}

The encoding of a message is the production of the message. It is a system of coded meanings, and in order to create that, the sender needs to understand how the world is comprehensible to the members of the audience (Castleberry, 2015). Thus barcode encoding is the process of entering the information about the product into the 
data base of the products stock of the business. Barcode encoding would require the supermarkets to stock in their product line information into the access chip of the firm's soft ware to assign a readable field to the assorted products so as to easily identify the products during assortment (La Moreaux, 1998).

In the process of encoding, the sender (i.e. encoder) uses verbal (e.g. words, signs, images, video) and nonverbal (e.g. body language, hand gestures, face expressions) symbols for which he or she believes the receiver (that is, the decoder) will understand (Michael \& Masters, 2004). The symbols can be words and numbers, images, face expressions, signals and/or actions. It is very important how a message will be encoded; it partially depends on the purpose of the message (Sarma, Brock \& Engels, 2001).

\section{Concept of Retailing Performance}

Ordinarily, retailing performance amongst retailing outlets comprises the actual output or results of an organization's endeavour as measured against its intended outputs. According to Richard et al. (2009) retailing performance encompasses three specific areas of firm's outcomes which include; financial performance of the retailing outlet (i.e profit, return on assets, return on investment); product market performance (sales volume, market share); and owner's return (economic value).

In retailing business, performance is probably the most widely used dependent variable in marketing research today; however, this concept remains one of the most loosely defined constructs. Precisely, the biggest challenge to retailing performance as a concept is the external environment, evidently, every retail organization operate within some external environment, thus the challenges that may arise could be political, economical, socio-cultural, environmental or technological in nature (Weatherspoon \& Reardon, 2002).

Suffice to state that the primary goal of any retailing business is to increase its sales effectiveness and efficiency, which is to improve the ability of the business to deliver goods to the final consumers (Orori, 2011). At the organizational level, performance usually involves softer forms of measurement such as, customers' satisfaction surveys which are used to obtain qualitative information about performance from the customers of the retail business (Jacobs, 2009).

\section{Sales Volume}

Sales volume can be referred to as the quantity of goods and services offered in the normal operations of a firm in a specific period (www.business dictionary.com/sales volume). According to Cavusgil (1996), sales volume can be defined as the quantity of total sales achieved in units or dollars. It explains important product development concepts as it provides the stake holders with the figures where analyses can be based to project further development.

Accordingly, Jobber and Lancaster (2000), states that the selling process is complicated by the fact that, there are usually several alternative ways by which each objective can be achieved. For instance, one can achieve an increase in revenue of $10 \%$ by increasing prices, increasing sales volume at the firm level that is market share or increasing industry sales. This illustrates how an increase in sales volume at the end of the day is expected to increase the revenue flow into to the firm. Sales volume is that units that are sold in a given time period. Its disadvantages are; firstly, emphasis is laid only on sales volume and not on profits. Secondly, it leads to imbalances in selling activity (Jobber, 1997)

According to Nobilis (2010), sales volume is seen as the core interest of every organization that is based on sales and profit. When the volume increases, all others are manageable (margin, profit, numerical distribution) but when the volume decreases, it becomes difficult to manage the business parameters. Sales does not increase or decrease on its own, the company manages and directs its sales volume through the portfolio and channels.

\section{Profitability}

The primary aim of every business transaction is to make profit. According to Lord Keynes (2008), profit is the engine which drives the business enterprise. Profitability can be defined as the surplus of a large number of policies and decisions (Weston \& Brigham, 2012). Profitability is the quality of affording gain or benefit (www.wordnetweb.princeton.edu). Profitability is simply the capacity to make a profit and a profit is what is left over from income earned after have deducted all cases and expenses related to earning the income (www.education-portal.com). Profitability is the ability of a particular investment to earn a return from its use (Howard \& Upton, 1961). Without profitability, the business will not survive in the long run .Therefore, measuring current and past profitability is very important

\section{Universal Product Code and Retailing Performance}

The modern automated information technology under which the Universal Product Code (barcode) is domiciled offers priceless means of doing business which yields a positive outcome. Through this process, in business, information on the business, items and contexts can be conveyed and stored without any form of paper documents or file (Walker, 2010). 
In order to carryout business activities, supermarkets are increasingly indulging in the use of universal product code (coding of products) in their operations and these have helped to improve on the procurement, assortment and sales capabilities of these supermarkets as product can be easily identified and their prices determined through the universal product coding system which has in turn enhanced the retailing abilities of the supermarkets (Walker, 2010).

The use of the Universal Product Code in coding the products (items) of supermarkets helps to save time wasted in grading and sorting of products by streamlining purchasing control. As a result of the universal product coding and automated product sorting and grading, tasks that previously took hours or even days can now be performed with a few clicks of a mouse (Heinen, Coyle \& Hamilton, 2003). Through this modern automated sorting and grading practice of coding, the staff of supermarkets no longer wastes time in matching receipts with deliveries, figuring out overly complex invoices and keying in redundant information (Hum \& Marciano, 2010). As a result of the use of the Universal Product Code, supermarkets will also enjoy a reduction in the administrative tasks involved with vendor management, customer control, staff line evaluation etc, instead, managers can spend more of their time analyzing the patterns of response of staff to customers and assessing the ease at which staff are able to put this universal product code encoding and decoding practice to use for the benefit of their employer(s) (Joshi, 2009). As argued by Joshi, (2009) the universal product coding of products creates a more efficient business model for business organizations (Supermarkets inclusive) eliminating unnecessary and time wasting activities and thus increasing profitability.

Atkinson (2010) stated that the use of the universal product coding system which is an automated solution enables supermarkets to reduce cost, save time, improve accuracy, enhance suppliers' negotiations and ensure compliance. The result therefore is a more streamlined operation, smarter purchasing/sales decisions and increased control over the supply and distribution chain of the supermarkets.

Joshi (2009) posits that an automated system (including the universal product code system) not only optimizes existing resources and prevents unnecessary costs, but also position the supermarkets for success in the short run and in future.

\section{Empirical Literature Review}

Practitioners as well as researchers have advocated the advantages of e-procurement. Jau-Jeng et al. (2008) conducted a study on the impact of web-based e-procurement on organizational performance. A significant finding is that the implementation of Web-based e-procurement can lead to better partnership between buyers and suppliers. By adopting a completeness Web-based e-procurement solution, buyers can enhance their partnerships with suppliers with respect to information sharing and technology dependence. Partner relationship contributes to both supplier performance and buyer performance, indicating that good partnership paves the way for sounding SCM operating environment.

A study conducted by Nepelski (2006) sought to find out how electronic procurement influences the organization of economic transactions. It sought evidence for ICT-induced 13changes in how companies organize their activities and whether ICT lead to more competitive and transparent markets. Testing the relationship between the effect of electronic procurement on procurement cost and sourcing strategy, it was revealed that electronic procurement leads to more market transactions. This led to the conclusion that electronic procurement increases market transparency, lowers search and supplier switching costs and improves the management of supply chain and contradicts the predictions that ICT will lead to a dominance of network-like organizational form and an increasing reliance on hybrid forms of organizing economic transactions.

A study by Akoth (2014) to investigate the relationship between e-procurement and organizational performance on NGOs in Nairobi, Kenya established that the accountability has been encouraged; there is a competitive bidding and sourcing and that there was improved flow of information. On the other hand, lack of management support; late supplier involvement; lack of proper staff training; failure to comply with best practices and poor information quality were the hindrances to the implementation of e-procurement. Further, the study concluded that online advertisement of tenders has improved effectiveness; online short listing of tenders has ensured transparency; online requisition by organization staff has improve accountability and online advertisement of tenders has ensured the NGO gets competitive suppliers.

Mose et al. (2013) revealed that majority of the large scale manufacturers in Nairobi, Kenya has adopted eprocurement with the following e-procurement practices: online advertisement of tenders, receiving online submission of proposals for the tenders, and short listing suppliers online among others. The five critical success factors identified were: employees and management commitment to success of adoption; reliability of information technology and supplier performance; monitoring the performance of e-procurement systems; user acceptance of e-procurement systems and top management.

Amin (2012) study on the electronic procurement and organizational performance among commercial state corporations revealed that commercial state corporations in Kenya have adopted e-procurement but there are several functions they still perform manually. These include, short listing of suppliers, call for proposals and 
tendering process. It was also established that e-procurement has led to cost reduction, improved transparency, and accountability among others. The findings also indicate that the e-procurement system has enabled commercial state corporations in Kenya to provide real time response of feedback to both customers and the market.

\section{Methodology}

\section{Research Design}

A research design has been described as a program, which guides the researcher in the process of collecting, analyzing and interpreting observation. It also connotes the structuring of investigation aimed to identify variables and their relationships to one another. Therefore, the researcher will use quasi-experimental design because there are both dependent and independent variables used in the model. The dependent variable is influenced by the independent variables which make Quasi-experimental research design appropriate for the study. Further, primary data was used to carry out the analysis. Therefore, the research design for this work involves the following steps:

(i) Data collation from managerial level staff of the supermarkets in Port Harcourt.

(ii) The analysis of data collected using the SPSS Version 22.0

\section{Model Specification}

The analysis involved the use of the Pearson's Product Moment Correlation Coefficient statistical tool. This was used to determine the perceived relationship between the independent and dependent variables.

Model, which is the simplification of complex reality, specifies the relationship between the variables used in the analysis. Therefore, the models specify that retailing performance of supermarkets in Port Harcourt [proxy by sales volume and profitability] is significantly influenced by bar code formatting and bar code encoding. The models, which are expressed in their natural forms, are formulated as follows,

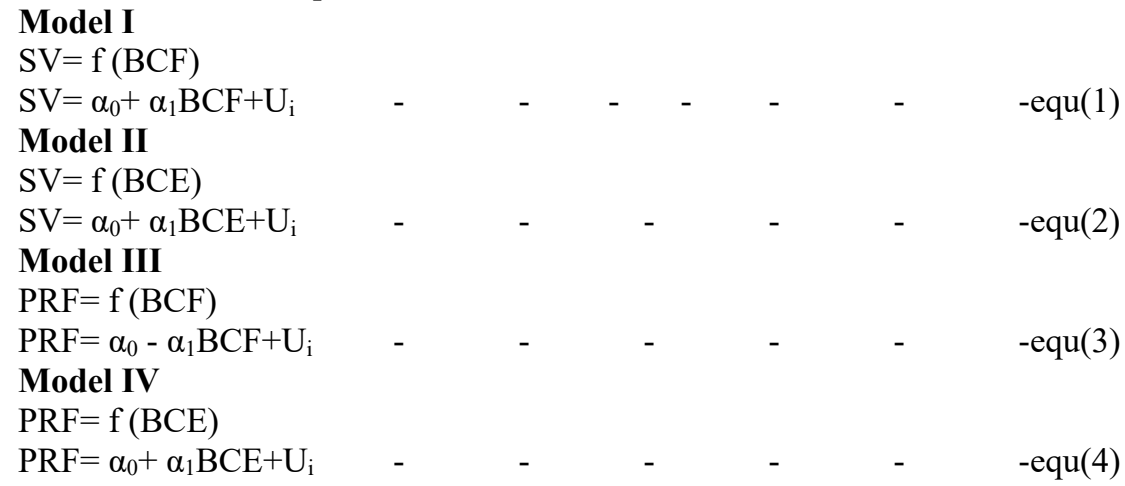

Where;

The a priori expectations are $\alpha_{1}>0$ for models I to IV.

$\mathrm{SV} \quad=\quad$ Sales Volume

PRF $\quad=\quad$ Profitability

$\mathrm{BCF} \quad$ Barcode Formatting

$\mathrm{BCE} \quad=\quad$ Barcode Encoding

$\mathrm{U}_{\mathrm{i}} \quad$ Disturbance Term

$\alpha_{0} \quad=\quad$ Intercept

$\alpha_{1} \quad=\quad$ Coefficient of the independent Variables

\section{Sources and Method of Data Collection}

The data for this study was obtained mainly from management level staff of supermarkets in Port Harcourt. One hundred copies of the research questionnaire were distributed; this was based on the researchers' convenience. However, only ninety two (92) copies were used for the analysis.

\section{Method of Data Analysis}

The study was to evaluate the relationship between Universal Product Code and retailing performance of supermarkets in Port Harcourt. Specifically, data collected for this study were analyzed with the aid of the Statistical Package for Social Scientists (SPSS) version 22.

The Pearson's Product Moment Correlation Coefficient statistical tool was used to determine the impact of the dimensions of the independent variable on the measures of the dependent variable.

\section{Analyses and Results}

The dimensions of Universal Product Code: barcode formatting and barcode encoding were correlated against the measures of the dependent variable which were sales volume and profitability. The aim was to ascertain if there is 
a significant relationship between these dimensions of Universal Product Code and the retailing performance measures, and also to determine the direction of such relationship. The Pearson's correlation coefficient statistics was used in analyzing the data collected for the purpose of this study, this was done with the aid of Statistical Package for Social Scientists (SPSS) version 22.

\section{Hypothesis One}

$\mathrm{HO}_{1}$ : There is no significant relationship between bar code formatting and sales volume of supermarkets in Nigeria.

\section{Statistical Analysis for Hypothesis One}

\begin{tabular}{|ll|r|r|}
\hline \multicolumn{2}{c}{ Correlations } \\
\hline \multirow{2}{*}{ Barcode } & Bearson Correlation & 1 & .955 \\
Formatting & Sig. (2-tailed) & & .044 \\
& $\mathrm{~N}$ & 92 & 92 \\
& Pearson Correlation & .955 & 1 \\
Sales Volume & Sig. (2-tailed) & .044 & \\
& $\mathrm{~N}$ & 92 & 92 \\
\hline
\end{tabular}

From the result of the above table, the correlation coefficient $(r=0.955)$ between barcode formatting and sales volume is very strong and positive.

The coefficient of determination $\left(r^{2}=0.91\right)$ indicates that $91 \%$ of sales volume can be explained by barcode formatting. The significant value of $0.044(p<0.05)$ reveals a significant relationship. Based on that, the null hypothesis was rejected. Therefore, there is a significant relationship between barcode formatting and sales volume of supermarkets in Port Harcourt.

\section{Hypothesis Two}

$\mathrm{HO}_{2}$ : There is no significant relationship between barcode formatting and profitability of supermarkets in Nigeria.

\section{Statistical Analysis for Hypothesis Two}

\section{Correlations}

\begin{tabular}{|ll|r|r|}
\hline & & Barcode Formatting & Profitability \\
\hline \multirow{2}{*}{ Barcode } & Pearson Correlation & 1 & .962 \\
Formatting & Sig. (2-tailed) & & .038 \\
& $\mathrm{~N}$ & 92 & 92 \\
& Pearson Correlation & .962 & 1 \\
Profitability & .038 & \\
& Sig. (2-tailed) & 92 & 92 \\
\hline
\end{tabular}

From the result of the above table, the correlation coefficient $(r=0.962)$ between barcode formatting and profitability is very strong and positive.

The coefficient of determination $\left(\mathrm{r}^{2}=0.925\right)$ indicated that $92.2 \%$ of profitability of the supermarkets can be explained by barcode formatting. The significant value of $0.038(\mathrm{p}<0.05)$ reveals a significant relationship. Based on that, the null hypothesis is rejected. Therefore, there is a significant relationship between barcode formatting and profitability of supermarkets in Port Harcourt.

\section{Hypothesis Three}

$\mathrm{HO}_{3}$ : There is no significant relationship between barcode encoding and sales volume of supermarkets in Nigeria. Statistical Analysis for Hypothesis Three

\section{Correlations}

\begin{tabular}{|ll|r|r|}
\hline & & Barcode Encoding & Sales Volume \\
\hline \multirow{5}{*}{ Barcode Encoding } & Pearson Correlation & 1 & .965 \\
& Sig. (2-tailed) & & .041 \\
& $\mathrm{~N}$ & 92 & 92 \\
& Pearson Correlation & .965 & 1 \\
Sales Volume & Sig. (2-tailed) & .041 & \\
& $\mathrm{~N}$ & 92 & 92 \\
\hline
\end{tabular}

From the result of the above table, the correlation coefficient $(\mathrm{r}=0.965)$ between barcode encoding and sales 
volume is very strong and positive.

The coefficient of determination $\left(\mathrm{r}^{2}=0.93\right)$ indicated that $93 \%$ of the sales volume of supermarkets can be explained by barcode encoding. The significant value of $0.041(\mathrm{p}<0.05)$ reveals a significant relationship. Based on that, the null hypothesis is rejected. Therefore, there is a significant relationship between barcode encoding and sales volume of supermarkets in Port Harcourt.

\section{Hypothesis Four}

$\mathrm{HO}_{4}$ : There is no significant relationship between barcode encoding and profitability of supermarkets in Nigeria. Statistical Analysis for Hypothesis Four

\begin{tabular}{|ll|r|r|}
\hline \multicolumn{2}{|c|}{ Correlations } \\
\hline \multirow{4}{*}{ Barcode Encoding } & Barcode Encoding & Profitability \\
& Pearson Correlation & 1 & .945 \\
& Sig. (2-tailed) & & .039 \\
& $\mathrm{~N}$ & 92 & 92 \\
& Pearson Correlation & .945 & 1 \\
Profitability & Sig. (2-tailed) & .039 & \\
& $\mathrm{~N}$ & 92 & 92 \\
\hline
\end{tabular}

From the result of the above table, the correlation coefficient $(r=0.945)$ between barcode encoding and profitability is very strong and positive.

The coefficient of determination $\left(\mathrm{r}^{2}=0.89\right)$ indicated that $89 \%$ of profitability in the supermarkets can be explained by barcode encoding. The significant value of $0.039(\mathrm{p}<0.05)$ reveals a significant relationship. Based on that, the null hypothesis is rejected. Therefore, there is a significant relationship between barcode encoding and profitability of supermarkets in Port Harcourt.

\section{Conclusion}

Based on the finding as revealed by the study, the following conclusions are made:

i.) A positive and significant relationship exists between barcode formatting and sales volume of supermarkets in Nigeria.

ii.) Bar code formatting enhances the profitability of supermarkets in Nigeria.

iii.) There is a significant relationship between barcode encoding and sales volume of supermarkets in Port Harcourt.

iv.) Barcode encoding enhances the profitability of supermarkets in Nigeria.

\section{Recommendations}

i) Supermarkets should endeavour to update regularly, their products barcode fields to ensure that their wide range of products are always captured and enlisted in the field to ease up the purchase and sales activities of the supermarkets.

ii) Regular training exercise should be organized to educate the staff of the supermarkets on how to manage the barcode fields and to efficiently handle issues relating to formatting and encoding of the barcode fields

\section{References}

Akoth, M. (2014). E-Procurement and organizational performance of non-governmental organizations in Nairobi, Kenya. Unpublished MBA Project, University of Nairobi, Nairobi, Kenya.

Amin, K.A. (2012). Electronic procurement and organizational performance among commercial state corporations. Unpublished MBA Project, University of Nairobi, Nairobi, Kenya

Brown, S.A. (1997). Revolution at the checkout counter: The explosion of the bar code. Harvard University Press, London.

Burnell, J. (1998). Technology tames logistics - matching information flow to material flow is key to benefits in logistics and supply chain management programs. May/June. Automatic I.D. News Asia.

Castleberry, G. (2015). Understanding Stuart hall's 'encoding/decoding' through AMC's breaking bad. In Glenister Roberts, Kathleen (ed.), Communication theory and millennial popular culture: Essays and applications (p. 90). New York City: Peter Lang Inc.

Cavusgil, H. (1996). Marketing in Practice. Prentice Hall.

Cohen, J. (1994). Automatic identification and data collection systems. McGraw-Hill Book Company, London. Harward \& Upton (1961). Introduction to business finance. McGraw Hill, New York.

Heinen, M.G., Coyle, G.A., \& Hamilton, A.V. (2003). Barcoding makes its mark on daily practice. Nursing Management, (p. 18). [Online] Available ProQuest, Document ID: 442886571. Last accessed 17/10/2004.

Jacobs, F. R. (2009). Operations and supply management. $\left(12^{\text {th }}\right.$ Ed), Indiana University. 
Jobber (1997). The CIM handbook of sellers and sales strategy. Butter Worth Heinemann.

Jobber, D., \& Lancaster (2000). Selling and sales management. Prentice Hall.

LaMoreaux, R.D. (1998). Barcodes and other automatic identification systems. Pira International, New York.

Michael, K., \& Masters, A. (2004). Applications of human transponder implants in mobile commerce. University of Wollongong.

Mose et al. (2013). The critical success factors and challenges in e-procurement adoption among large scale manufacturing firms in Nairobi, Kenya. European Scientific Journal, 9(13).

Nepelski, D. (2006). The impact of e-procurement on the number of suppliers. Where to move to? Information Society and Competition, German Institute for Economic Research

Nobilis (2010). E-marketing today.

Orori, J. M. (2011). Factors that influence the introduction of e-procurement in retail industry: A survey of retail chain supermarkets in Kenya. Unpublished Research, Jomo Kenyatta University of Agriculture and Technology.

Palmer, R.C. (1995). The bar code book- reading, printing and specification of bar code symbols. Helmers Publishing Inc., New Hampshire.

Richard et al. (2009). Measuring organizational performance: Towards methodological best practice. Journal of Management

Sarma, S., Brock, D., \& Engels, D. (2001). Radio frequency identification and the electronic product code. MIT Auto-ID Center. IEEE Micro.

Swartz, J. (1999). The growing 'MAGIC' of automatic identification. IEEE Robotics \& Automation Magazine, 20-22, 56.

Weatherspoon, D., \& Reardon, T. (2002). The rise of supermarkets in Africa: Implications for Agrifood systems and the rural poor. Development Policy Review, 21(3).

Weston, J.F., \& Brigham, E.F. (2012). Essential of Managerial Finance.

www.worldnetweb.princeton.edu 